\section{General Atomic's new fusion venture}

\section{from David Fishlock}

WHILE discussions continue on the design-and location-of JET, the Joint European Tokamak, plans are ready for a start in La Jolla next month on the first of the new generation of thermonuclear fusion machines. These are the machines plasma physicists believe will demonstrate later this decade the feasibility of fusion, by reaching 'break-even'-the point at which the experiment's energy output equals the input.

Dr Tihiro Ohkawa, head of fusion research at General Atomic, the joint nuclear venture between Gulf Oil and Royal Dutch-Shell, has received approval from the United States Atomic Energy Commission for his plans for Doublet III. If all goes well by about the end of 1977 Doublet III will be ready to demonstraie plasma confinement times as long as one second.

Doublet III is the successor to a very successful experiment in magnetic containment called Doublet II, carried out by General Atomic between 1971 and 1973. Dr Ohkawa demonstrated how the plasma itself could be used as an electrical conductor to generate intense magnetic fields that remain unperturbed by the plasma. Doublet III will be a large scale version of this experiment and is expected to cost about $\$ 26$ million.

A site has been chosen in the valley below General Atomic's hilltop research campus, so that the power lines supplying some 5 million amperes can conveniently be kept out of sight. The dumpling-shaped structure, some 13 feet tall and 18 feet in diameter, is expected to take 3-5 years to complete. Meanwhile, to assist the designers Doublet II has been stripped down and is now being rebuilt as Doublet IIA, with magnetic facilities for fine tuning the plasma configuration.

In the late $1960 \mathrm{~s}$, when the physics of fusion was still in chaos, Dr Ohkawa's fusion research group suffered far more severely than the British Culham Laboratory. After Texan utilities withdrew their support his group numbered no more than seven. But, encouraged by Dr C. L. Rickard, vicepresident in charge of advanced systems development, Ohkawa rebuilt confidence among sponsors. Today he can boast the largest fusion team in the private sector anywhere in the world. It numbers 80 and this year will spend about $\$ 7$ million. Next year it will number 120 .

It draws these funds from three sources-the company, a group of electrical utility sponsors and the United States Atomic Energy Commission. Of this year's research budget, about $\$ 2$ million is being spent on plasma physics, $\$ 4$ million on large fusions systems (mostly Doublet IIA) and the remaining $\$ 1$ million on technology for the fusion reactor. But this lasi sector is expected to grow quickly, so that by 1980 it will be at least the size of the other two parts of the programme.

Already a conceptual design is taking shape of a candidate for the prototype fusion reactor which the Atomic Energy Commission hopes to start building in 1976. General Atomic is thinking in terms of a reactor based on Doublet III that will 'piggyback' on the company's experience with helium cooled fission reactors. Instead of using a liquid-metal-cooled system, as is usually proposed for extracting heat from a fusion reaction, it plans to use helium as the coolant and to drive gas turbines directly with the hot but inactive gas. For the preseni, therefore, Dr Ohkawa is confining his forays into fusion reactor technology to work on a ceramic torus - of silicon carbide and carbon-in which the plasma will be confined.

\section{Death-blow dealt to Moscow seminar}

from Vera Rich

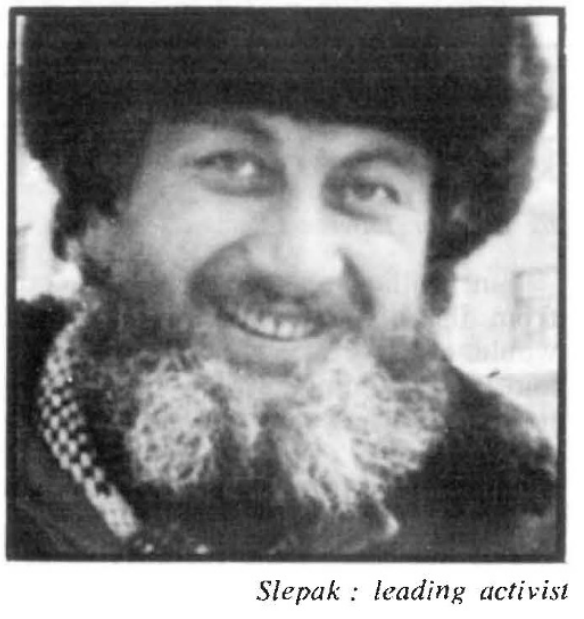

INTENSII IED pressure on the part of the Soviet authorities would seem to have dealt a death-blow to the Moscow 'underground" seminar on "Collective Phenomena and the Applications of Physics to Other Fields of Science" scheduled for July 1-5, 1974. A wave of arrests in the Soviet Union of Jewish dissidents. supposedly in connection with security arrangements for the Nixon visit, coupled with the blocking of visa applications from intending foreign participants, almost certainly mean that the seminar can no longer take place as originally envisaged.
The campaign began, apparently, on Wednesday, June 19, with an attempt to arrest an electronics engineer, Vladimir Slepak, who, although not a member of the Seminar Programme Committee, is a leading Jewish activist in the Soviet Union. Slepak apparently resisted arrest by barricading himself into his apartment; on Friday, however, the police broke in with crowbars. It is reported that when his fifteen-year-old son Leonid attempted to contact western journalists by telephone, the KGB intervened.

On the same day, Committee Member Viktor Brailovskii, in hiding to avoid forcible conscription, failed to keep a prearranged telephone contact with the international organisers of the seminar, while a telephone call to Tanya Levich (the wife of committee member Venyamin Levich) was established and cut off three times so that no message could be conveyed. It now seems that Lerner, Brailovskii and also committee members Mark Azbel, Aleksandr Lunts and Aleksandr Voronel were arrested on Friday or Saturday. Voronel, whose Moscow apartment was to have been the venue of the seminar, was arrested at the home of a friend. $\mathrm{He}$ is reported to have "given himself up" to the police-in view of the details of Slepak's arrest, however, this probably means no more than that he opened the door to them. Since all contacts between the dissidents and the outside world have now been broken, it is quite possible that this list of arrests is by no means complete.

Simultaneously with the news of the arrests, the foreign "participants" learned that they themselves would not be able to travel to Moscow. Some 40 scientists from the United States (including seven Nobel Prize winners) have been refused visas. Similar refusals are reported from Israel and France. The British contingent, for whom more details are available, reveal an interesting picture of blocking tactics. Those intending to travel alone were told, on submitting their applications, that they must provide an official invitation from some recognised scientific organisation in the Soviet Union (which, of course, they were unable to do). Since then they have heard no more of their applications. The others, who planned to travel as a group, have not met a definite refusal; but since the last date by which the travel agents needed visa clearance in order to complete the necessary arrangements has now passed, this amounts to de facto refusal.

Asked to comment on the situation Dr Norman Chigier of the University of Sheffield, one of the three International Secretaries of the Seminar, observed: "It appears that the Soviet authorities are determined to destroy the seminar". 